Watanabe, T. \& Watanabe, M. (1959). J. gen. Microbiol. 21, 30-39

\title{
Transduction of Streptomycin Sensitivity into Resistant Mutants of Salmonella typhimurium
}

\author{
By T. WATANABE* AND M. WATANABE \\ Department of Zoology, Columbia University, Nerv York 27, N.Y., U.S.A.
}

SUMMARY: The infection of slow-growing one-step intermediate streptomycinresistant mutants with phage from wild-type bacteria, indifferent (one-step completely resistant) or other one-step intermediate resistant mutants gives rise to fastgrowing streptomycin-sensitive transductants. From this fact it is clear that both slow growth and streptomycin resistance are controlled by a single locus. The transductants are very easily detected on the poor background growth of the intermediate resistant recipient. With this technique it has become possible to cross one-step resistance with resistance, indifference and sensitivity. The results so far obtained indicate that one-step intermediate resistance is controlled by multiple loci. None of these loci is linked to the indifference locus. The fast-growing mutants which develop from the two-step resistant mutants are assumed from the transduction analysis to be due to reverse mutations at the first step loci.

In a preceding paper Watanabe \& Watanabe (1959) reported that streptomycin indifference (one-step complete resistance) is easily transduced into sensitive or intermediate resistant bacteria. On the other hand, the transduction into sensitive recipients of intermediate resistance obtained by one-step and twostep selection is not easily detected, even when the delay in phenotypic expression is taken fully into consideration. None the less, sensitive alleles can be transduced into intermediate resistant mutants as will be reported in the present paper.

Since it was established that streptomycin indifference is controlled by a single locus (Watanabe, 1954), it is easily assumed that the streptomycin sensitive allele will also be transduced into indifferent mutants, although on account of the lack of proper selective methods it may not be easy to detect the sensitive transductants among the indifferent cells. On the other hand, as described before (Watanabe, 1954; Watanabe \& Watanabe, 1959), all of the intermediate streptomycin-resistant mutants are slow growers, and from them fast-growing sensitive or less resistant mutants come out spontaneously. Indeed, in the case of one-step intermediate resistant cells infection with phage from wild-type bacteria was found to give rise to fast-growing streptomycin sensitive transductants. This finding has led us to the transductional analysis of various types of streptomycin resistant mutants by looking for wild-type transductants rather than by looking for resistant transductants.

\footnotetext{
* Present address: Department of Bacteriology, Keio University School of Medicine,
} Tokyo, Japan. 


\section{METHODS}

The system of Salmonella typhimurium, strain LT-2, and temperate phage PLT-22 was used exclusively. The indifferent mutants were those which were described in a preceding paper (Watanabe \& Watanabe, 1959). For detecting the sensitive transductants among the indifferent mutants, streptomycin-free agar plates seeded with about 500 infected bacteria on their surface were replicated on agar plates containing $500 \mu \mathrm{g}$. $/ \mathrm{ml}$. of streptomycin and colonies on the master plates which did not give resistant colonies on replica plates were looked for.

In order to isolate independent intermediate resistant mutants, liquid medium containing about 100 cells of wild-type bacteria per ml. was distributed into many test tubes in $1 \mathrm{ml}$. amounts. After incubation for $18 \mathrm{hr}$. at $37^{\circ}$, $0.1 \mathrm{ml}$. of each culture was plated on agar medium containing 25, 50, 100 and $250 \mu \mathrm{g}$. streptomycin $/ \mathrm{ml}$. The inoculated plates were incubated at $37^{\circ}$ for 5 days and three colonies were picked at random from each plate and purified by repeating single colony isolations on streptomycin-free agar. Plates which contained $250 \mu \mathrm{g}$. streptomycin $/ \mathrm{ml}$. developed few or no colonies. The mutants thus obtained were used as one-step resistant mutants; the method of isolating two-step resistant mutants has been described elsewhere (Watanabe \& Watanabe, 1959). In transduction experiments with intermediate resistant bacteria, previously mentioned precautions were taken to avoid spontaneous fast-growing mutants (Watanabe \& Watanabe, 1959).

The media used have also been described in the same publication.

\section{RESULTS}

Transduction of sensitivity into indifferent bacteria

As reported in a preceding paper (Watanabe \& Watanabe, 1959), indifference from both fast- and slow-growing strains can be transduced into sensitive bacteria with about equal frequencies and the obtained indifferent transductants are all fast growers in both cases. In an attempt to transduce sensitivity into indifferent mutants, fast-growing indifferent mutants were first used and possible sensitive transductants were looked for with the replica plating technique. More than 10,000 colonies, developing on master plates from indifferent bacteria infected with phage from wild-type bacteria at multiplicities of input 5 and 100 were replicated on streptomycin agar plates. None of them was found to be sensitive to streptomycin. The frequency of transduction of sensitivity into indifferent bacteria seems, therefore, to be lower than $10^{-4}$, if there is any such transduction. This fact is not surprising from experience with the transduction of other markers. It may be possible to discover sensitive transductants, if very many more plates are replicated in the above way.

Next, slow-growing indifferent mutants were used as recipients. When large numbers of recipient bacteria infected with phage from wild-type bacteria were plated on agar plates without streptomycin, it was found that fast- 
growing colonies developed on the poor background growth. They were replicated on agar plates containing $1000 \mu \mathrm{g}$. streptomycin $/ \mathrm{ml}$. and more than 500 colonies replicated were all found to be resistant to streptomycin at this concentration. From this result it will be understood that the slow growth and the indifference of the slow-growing indifferent mutants are possibly controlled by two different loci. Thus the detection of sensitive transductants cannot be facilitated by using slow-growing indifferent mutants as recipients and looking for large colonies, because in these large colonies only the locus which controls slow growth seems to have been replaced by transduction.

\section{Transduction of sensitivity into one-step intermediate resistant bacteria with phage from wild-type bacteria}

The infection of one-step resistant mutants with phage from wild-type bacteria gave large colonies on a background of poor growth; whereas control plates spread with bacteria infected with homologous phage and uninfected by phage gave no large colonies. In some experiments the control plates gave some large colonies of spontaneous fast-growing mutants; these experiments were repeated.

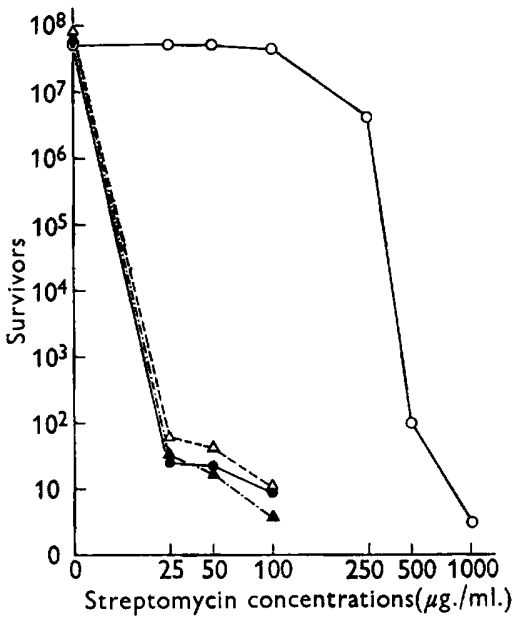

Fig. 1

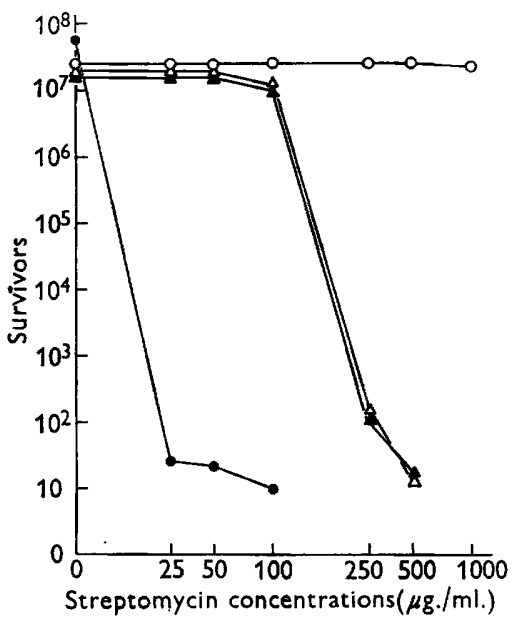

Fig. 2

Fig. 1. Survival curves, in streptomycin, of Salmonella typhimurium, strain LT-2 wild-type, the one-step resistant mutant $\mathbf{A}$, fast-growing transductants developed from mutant $A$ with phage from wild-type bacteria. Varying dilutions of each bacterial suspension were plated on agar medium containing varying concentrations of streptomycin and the colonies developed were scored after 5 days' incubation of the inoculated plates. $\bigcirc-O$, Mutant $A ; \Delta--\triangle$, wild-type transductant no. $1 ; \Delta--\Delta$, wild-type transductant no. 2; - - , wild-type.

Fig. 2. Survival curves, in streptomycin, of Salmonella typhimurium, strain LT-2 wild-type, the two-step resistant mutant B/1000, fast-growing mutant and transductant derived therefrom. Varying dilutions of each bacterial suspension were plated on agar medium containing varying concentrations of streptomycin and the colonies developed were scored after 5 days' incubation of the inoculated plates. $\bigcirc-O$, Mutant $B / 1000$; $\Delta-\Delta$, fast-growing transductant; $\Delta-\Delta$, fast-growing mutant; $0-0$, wild-type. 
In studying the transduction of sensitivity into one-step intermediate resistant bacteria, it was found that the fast-growing transductants were invariably as sensitive to streptomycin as the wild-type bacteria. This was found with replica plating as well as survival curve determinations (Fig. 1). In addition, spontaneous fast-growing mutants developed from one-step resistant mutants were also found to have a sensitivity to streptomycin equal to wild-type bacteria. These facts seem to suggest that both the slow growth and the streptomycin resistance of the one-step intermediate resistant mutant are controlled by a single locus. For this reason the fast-growing sensitive transductants are called wild-type transductants.

The frequencies of wild-type transductants varied considerably according to the recipient when phage from wild-type was used as a donor as shown in Table 1. Some of the one-step intermediate resistant mutants were found to give only small numbers of wild-type transductants.

Table 1. Transduction of sensitivity into one-step intermediate streptomycin resistant bacteria in Salmonella typhimurium, strain LT-2, with phage grown on wild-type and indifferent bacteria

\begin{tabular}{|c|c|c|}
\hline \multirow[b]{2}{*}{ Recipient } & \multicolumn{2}{|c|}{$\begin{array}{l}\text { No. of wild-type transductants } \\
\text { in } 0.1 \mathrm{ml} \text {. of phage-infected } \\
\text { bacteria }\end{array}$} \\
\hline & $\begin{array}{l}\text { With } \\
\text { phage from } \\
\text { wild-type } \\
\text { bacteria }\end{array}$ & $\begin{array}{l}\text { With } \\
\text { phage from } \\
\text { indifferent } \\
\text { bacteria }\end{array}$ \\
\hline $100 \mathrm{M}(100 \mu \mathrm{g} . / \mathrm{ml} .-$ resistant $)$ & 3 & 2 \\
\hline $250 \mathrm{C}(250 \mu \mathrm{g} . / \mathrm{ml} .-$ resistant $)$ & 4 & 6 \\
\hline 25-1 A (25 $\mu$ g./ml.-resistant) & $\mathbf{2 5}$ & 23 \\
\hline 50-2 B (50 $\mu \mathrm{g} . / \mathrm{ml} .-$ resistant) & 46 & 33 \\
\hline 250-2A (250 $\mu \mathrm{g} . / \mathrm{ml}$. -resistant) & $\mathbf{3}$ & $\mathbf{5}$ \\
\hline $100-3 \mathrm{~A}(100 \mu \mathrm{g} . / \mathrm{ml} .-$ resistant $)$ & 48 & 48 \\
\hline 50-5A (50 $\mu \mathrm{g} . / \mathrm{ml}$. -resistant) & 34 & 35 \\
\hline 25-7 A (25 $\mu \mathrm{g} . / \mathrm{ml} .-$ resistant $)$ & 26 & 25 \\
\hline 25-8A (25 $\mu \mathrm{g} . / \mathrm{ml}$.-resistant) & 31 & 26 \\
\hline 50-9 B (50 $\mu \mathrm{g} . / \mathrm{ml} .-$ resistant $)$ & 26 & 58 \\
\hline 25-10A (25 $\mu \mathrm{g} . / \mathrm{ml}$.-resistant $)$ & 26 & 40 \\
\hline 50-12A (50 $\mu \mathrm{g} . / \mathrm{ml}$.-resistant) & 360 & 320 \\
\hline 25-13A (25 $\mu \mathrm{g} . / \mathrm{ml} .-$ resistant) & $\mathbf{2 5}$ & $\mathbf{3 3}$ \\
\hline $100-14 \mathrm{~A}(100 \mu \mathrm{g} . / \mathrm{ml}$.-resistant $)$ & 200 & 178 \\
\hline
\end{tabular}

Equal volumes of a recipient bacterial suspension (about $10^{\circ} / \mathrm{ml}$.) and phage $\left(10^{10} / \mathrm{ml}\right.$.) from either wild-type or indifferent bacteria were mixed and aerated at $37^{\circ}$ for $10 \mathrm{~min}$., when $0.1 \mathrm{ml}$. of undiluted infected culture was plated on agar without streptomycin. Large colonies were counted after incubating the plates for $\mathbf{2}$ days.

\section{Transduction of sensitivity into one-step resistant bacteria with phage from indifferent mutants}

All strains of intermediate resistant bacteria infected with phage grown on fast-growing as well as slow-growing indifferent mutants gave numbers of wild type transductants approximately equal to the numbers found when phage from wild-type bacteria was used as shown in Table 1. None of the 
fast-growing transductants was found to be resistant to streptomycin. Therefore, the loci which control one-step intermediate resistance are not closely linked to that of streptomycin indifference.

Table 2. Transduction of sensitivity into one-step intermediate streptomycin resistant mutants of Salmonella typhimurium, strain LT-2, with phage grown on the one-step intermediate resistant mutant

\begin{tabular}{|c|c|c|c|c|c|}
\hline & $\begin{array}{l}\text { No. of wi } \\
\text { transductant } \\
\text { of phage-infec }\end{array}$ & $\begin{array}{l}\text { d-type } \\
\text { in } 0.1 \mathrm{ml} \text {. } \\
\text { ed bacteria }\end{array}$ & & $\begin{array}{l}\text { No. of w } \\
\text { transductant } \\
\text { of phage-infec }\end{array}$ & $\begin{array}{l}\text { ld-type } \\
\text { in } 0.1 \mathrm{ml} \text {. } \\
\text { ed bacteria }\end{array}$ \\
\hline Recipient & $\begin{array}{l}\text { When } \\
\text { infected with } \\
\text { phage from } \\
\text { mutant B }\end{array}$ & $\begin{array}{c}\text { Control } \\
\text { with } \\
\text { no phage }\end{array}$ & Recipient & $\begin{array}{c}\text { When } \\
\text { infected with } \\
\text { phage from } \\
\text { mutant B }\end{array}$ & $\begin{array}{c}\text { Control } \\
\text { with } \\
\text { no phage }\end{array}$ \\
\hline $\mathbf{A}$ & 18 & 0 & $25-4 B$ & 279 & $\mathbf{0}$ \\
\hline $100-1 \mathrm{~B}$ & 281 & 0 & $100-4 B$ & 12 & 1 \\
\hline 25-1 C & 116 & $\mathbf{0}$ & $25-4 C$ & 63 & 0 \\
\hline $100-1 \mathrm{C}$ & 45 & $\mathbf{0}$ & $50-4 A$ & c. 1000 & $\mathbf{0}$ \\
\hline $50-1 \mathrm{~A}$ & $\mathbf{0}$ & 0 & $50-4 B$ & 210 & $\mathbf{0}$ \\
\hline $50-1 \mathrm{~B}$ & 98 & 85 & $50-4 \mathrm{C}$ & 146 & $\mathbf{0}$ \\
\hline $50-1 \mathrm{C}$ & o & $\mathbf{0}$ & $25-5 B$ & $\mathbf{3}$ & 0 \\
\hline 25-2A & c. 1000 & 0 & $25-5 \mathrm{C}$ & 0 & 0 \\
\hline $50-2 A$ & 44 & 10 & $25-6 \mathrm{~A}$ & 12 & 0 \\
\hline $50-2 \mathrm{C}$ & 18 & 0 & $50-6 \mathrm{C}$ & 11 & 0 \\
\hline $100-2 C$ & 8 & o & $100-6 A$ & 157 & 18 \\
\hline $25-3 A$ & 0 & 0 & $100-6 \mathrm{C}$ & 78 & 22 \\
\hline $50-3 \mathrm{~A}$ & 242 & $\mathbf{0}$ & $* 25-7 \mathrm{~A}$ & $88(26)$ & 1 \\
\hline $25-3 C$ & $\mathbf{0}$ & 0 & 25-7B & 93 & 0 \\
\hline $50-3 \mathrm{C}$ & 40 & $\mathbf{0}$ & $25-7 \mathrm{C}$ & 86 & $\mathbf{0}$ \\
\hline $250-3 A$ & 457 & 2 & $50-7 \mathrm{~A}$ & 80 & 0 \\
\hline $100-3 \mathrm{~B}$ & 55 & 0 & $50-7 B$ & 81 & o \\
\hline $25-4 A$ & $\mathbf{0}$ & $\mathbf{0}$ & $* 25-8 \mathrm{~A}$ & $75(31)$ & $\mathbf{0}$ \\
\hline $100-4 \mathrm{~A}$ & 17 & 11 & $100-8 \mathrm{C}$ & 0 & 0 \\
\hline
\end{tabular}

* These are the only strains also in Table 1 (wild-type transductants in parentheses).

Equal volumes of phage grown on one-step mutant $B(100 \mu \mathrm{g} . / \mathrm{ml}$.-resistant $)\left(10^{10} / \mathrm{ml}\right.$. $)$ and bacterial suspension (about $10^{9}$ cells $/ \mathrm{ml}$.) were mixed and aerated at $37^{\circ}$ for $10 \mathrm{~min}$., when $0.1 \mathrm{ml}$. of the phage-infected bacterial suspension was spread on agar without streptomycin. For the control experiment, an equal amount of liquid medium was added instead of phage. Large colonies were counted after incubating the plates for 2 days.

\section{Transduction of sensitivity into one-step intermediate resistant bacteria with phage grown on other intermediate resistant mutants}

When many independently isolated mutant strains of one-step intermediate resistance were infected with a phage stock grown on a certain strain of onestep intermediate resistance, it was found that some of the strains gave various numbers of wild-type transductants, while some gave none (Table 2). The mutant strains which gave no wild-type transductants may be grouped together and the mutant strains which gave wild-type transductants may be put into different groups. With this grouping several classes can be found among the relatively stable one-step intermediate resistant mutants. A part of reciprocal transduction results among one-step intermediate resistant mutants of different groups is shown in Table 3. 
Transduction of sensitivity into one-step intermediate resistant bacteria with phage from two-step intermediate resistant mutants

When two-step intermediate resistant mutants were derived from one-step resistant mutants, they were invariably slow growers like the one-step mutants. The infection of one-step intermediate resistant mutants with phage from the two-step intermediate resistant mutants which are supposed to have the same first step was found to give no fast-growing transductants as shown in Table 4. However, when phage from a two-step resistant mutant which was derived from one-step resistant bacteria of a different group was used as a donor, many fast-growing transductants were obtained and they were all found to be sensitive to streptomycin as seen in this table.

Table 3. Reciprocal transduction of sensitivity into one-step streptomycin resistant mutants among independently isolated mutant strains of Salmonella typhimurium, strain $L T-2$

\begin{tabular}{|c|c|c|c|}
\hline \multirow[b]{2}{*}{ Recipient } & \multicolumn{3}{|c|}{$\begin{array}{l}\text { No. of wild type transductants developed } \\
\text { with donor phage grown on }\end{array}$} \\
\hline & $50-4 B$ & $50-8 \mathrm{~A}$ & 25-12A \\
\hline $50-4 \mathrm{~B}(50 \mu \mathrm{g} . / \mathrm{ml} .-$ resistant $)$ & 0 & 68 & 105 \\
\hline 50-8A (50 $\mu \mathrm{g} . / \mathrm{ml}$.-resistant) & 8 & 0 & 158 \\
\hline 25-12A (25 $\mu \mathrm{g} . / \mathrm{ml}$.-resistant $)$ & 87 & 329 & 0 \\
\hline
\end{tabular}

Equal volumes of donor phage $\left(10^{10} / \mathrm{ml}\right.$.) and recipient bacteria (about $5 \times 10^{9} / \mathrm{ml}$.) were mixed and aerated at $37^{\circ}$ for $10 \mathrm{~min}$., when $0.1 \mathrm{ml}$. of the infected bacterial suspension was plated on agar without streptomycin. Large colonies were counted after incubating the plates for 2 days.

Table 4. Transduction of sensitivity into one-step intermediate streptomycin resistant mutant of Salmonella typhimurium, strain LT-2, with phage grown on two-step resistant mutants

No. of wild-type transductants in $0.1 \mathrm{ml}$. of

Donor phage-infected bacteria

None

Phage from wild-type bacteria

Phage from one-step mutant $B$

(100 $\mu \mathrm{g} . / \mathrm{ml}$.-resistant)

Phage from two-step mutant B/1000

(1000 $\mu \mathrm{g} . / \mathrm{ml}$.-resistant)

Phage from one-step mutant $\mathrm{C}$

(250 $\mu \mathrm{g} . / \mathrm{ml}$.-resistant)

Phage from two-step mutant C/1000

980

(1000 $\mu \mathrm{g} . / \mathrm{ml} .-$ resistant)

Equal volumes of phage $\left(10^{10} / \mathrm{ml}\right.$.) and suspension (about $10^{9} \mathrm{cells} / \mathrm{ml}$.) of one-step mutant B $\left(100 \mu \mathrm{g} . / \mathrm{ml}\right.$.-resistant) were mixed and aerated at $37^{\circ}$ for $10 \mathrm{~min}$., when $0 \cdot 1 \mathrm{ml}$. of the phage-infected bacterial suspension was spread on agar without streptomycin. Large colonies were counted after incubating the plates for 2 days.

Mutants $\mathrm{B}$ and $\mathrm{C}$ were found by transduction to belong to different groups. 
Transduction of fast growth into two-step resistant bacteria with the phage either from wild-type bacteria, one-step resistant, indifferent or spontaneous fastgrowing mutants

As shown in Table 5, all of the phage from wild-type, one-step resistant, indifferent and spontaneous fast-growing mutants were found to give fastgrowing transductants with about equal frequencies. The fast-growing transductants developed from two-step resistant bacteria, however, were found not to be sensitive to streptomycin but still of intermediate resistance (Table 5 and Fig. 2). We have previously reported (Watanabe, 1954) that the fast-growing mutants which developed spontaneously from multiple-step resistant mutants are less resistant to streptomycin than their parents but not as sensitive as the wild-type. The transduction experiment described here seems to indicate that the fast-growing intermediate resistant transductants derived from the two-step mutants have recovered fast growth by the replacement of the firststep mutant locus with its wild-type allele, although they still retain the second-step mutant allele. If this is the case, a question may come up why one does not find this second step occurring as an independent mutation, i.e. a

Table 5. Transduction of fast growth into two-step intermediate streptomycin resistant bacteria of Salmonella typhimurium, strain LT-2, with phage grown on either wild-type bacteria, one-step intermediate resistant, indifferent or spontaneous fast-growing mutants

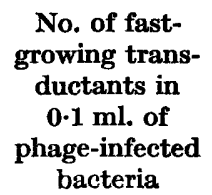

None

Phage from wild-type bacteria

Phage from two-step mutant B/1000

(1000 $\mu \mathrm{g} \cdot / \mathrm{ml} .-$ resistant)

Phage from one-step mutant $\mathrm{C}$

(250 $\mu \mathrm{g} . / \mathrm{ml}$.-resistant)

Phage from fast-growing mutant from B/1000

Phage from indifferent mutant

\begin{tabular}{rr}
$\begin{array}{c}\text { No. of large colonies on } \\
\text { replica plates } \\
\text { containing streptomycin } \\
(\mu \mathrm{g} . / \mathrm{ml} .)\end{array}$ \\
\hline 25 & 100 \\
0 & 0 \\
834 & 108 \\
0 & 0 \\
920 & 135 \\
940 & 189 \\
1080 & 156
\end{tabular}

Equal volumes of phage $\left(10^{10} / \mathrm{ml}\right.$.) and suspension (about $10^{\circ}$ cells $/ \mathrm{ml}$.) of two-step mutant $B / 1000\left(1000 \mu \mathrm{g} . / \mathrm{ml}\right.$.) were mixed and aerated at $37^{\circ}$ for $10 \mathrm{~min}$., when $0 \cdot 1 \mathrm{ml}$. of the phage-infected bacterial suspension was spread on agar without streptomycin. Large colonies were counted after incubating the plates for 2 days.

first-step, fast-growing mutant. Actually this type of mutant is not isolated, suggesting another possibility, i.e. the participation of suppressor mutations. For testing this possibility, the spontaneous fast-growing mutants developed from two-step resistant mutants were infected with phage from wild-type bacteria to see if any transductants with higher resistance came out by replacing the suppressor locus with its wild-type allele. In repeated experiments with several strains, however, no positive results were obtained. These 
negative data may indicate that at least such suppressors that are not closely linked to the resistance loci are not concerned with the decrease of resistance and recovery of fast growth in multiple-step resistant mutants.

\section{Nutritional requirements of one-step intermediate resistant mutants}

Although no auxotrophs were found among the intermediate streptomycin resistant mutants of Salmonella enteritidis, strain no. 11, and Escherichia coli, strains B-19 and K-12, despite the fact that they are invariably slow growers on complete media (Watanabe, 1954), some of the one-step intermediate resistant mutants of $S$.typhimurium, strain LT-2, were found to be auxotrophs. Furthermore, all of them were found to require both thiamine and nicotinic acid for their growth. Some of them are quite stable, while the others are fairly mutable. By transduction with phage grown on wild-type bacteria, this type of mutant is changed in a single step to wild-type which is fast growing, streptomycin sensitive and prototrophic; these characters never segregate from each other. Since the mutants of this group seem to be of particular interest from both genetic and biochemical viewpoints, their transductional and biochemical studies will be reported separately in a following paper.

\section{DISCUSSION}

In a preceding paper (Watanabe \& Watanabe, 1959), it was reported that streptomycin indifference (one-step complete resistance) is easily transduced, whereas intermediate resistance is not easily transduced. The apparent difficulty of transducing resistance into sensitivity even suggests the possibility that intermediate streptomycin resistance might be controlled by some cytoplasmic factors. If the loss of these factors were to cause the loss of streptomycin sensitivity, that is the development of streptomycin resistance, it is not surprising that streptomycin resistance is not transduced. In fact Sager (1954) reported that one type of streptomycin resistance in Chlamydomonas reinhardi is controlled by cytoplasmic factors.

The success of transduction of sensitive wild-type alleles into one-step resistant bacteria, however, seems to make the possibility of the participation of cytoplasmic inheritance of streptomycin resistance unlikely confirming the conclusion to be drawn from the fact that there are frequent fast-growing streptomycin sensitive spontaneous mutants. These spontaneous mutants of wild-type phenotype were found to have the wild-type allele at the locus of first-step resistance by transduction experiments in that the phage from these spontaneous mutants was found to be able to transduce fast growth and streptomycin sensitivity into one-step resistant bacteria in a single step. Before we succeed in showing that the loci for streptomycin resistance are linked to some other chromosomal markers, it is not possible to draw a decisive conclusion about the chromosomal nature of streptomycin resistance.

We have pointed out before (Watanabe, 1954) that streptomycin indifference is a rather exceptional type of resistance to antibiotics; the usual feature of drug resistance is quantitative variation. Demerec (1948) assumed that both 
streptomycin and penicillin resistance are controlled by multiple genes but in his later work (Demerec, 1950) he reported that streptomycin resistance is controlled by a single locus or by very closely linked loci.

The fact that the infection of slow-growing indifferent mutants with phage from wild-type gives fast-growing indifferent transductants seems to show that the slow growth of this type of indifferent mutant is due to a secondary mutation at a locus other than the indifference locus. Furthermore, the infection of wild-type bacteria with phage from slow-growing indifferent mutants was found to give fast-growing indifferent transductants.

The transduction of fast growth and streptomycin sensitivity into one-step intermediate resistant bacteria with phage from wild-type bacteria, indifferent mutants or other intermediate resistant mutants indicates that both slow growth and one-step intermediate streptomycin resistance are controlled by a single locus. The fact that the replacement of the first-step resistance locus of two-step resistant bacteria with its wild-type allele gives fast-growing intermediate resistant transductants shows that the second-step resistance locus may control only resistance and not slow growth. Although much attention has to be paid to the fact that fast-growing, intermediate streptomycin resistant mutants are not isolated by one-step selection with streptomycin, the failure to prove suppressor mutations for the decrease of resistance and recovery of fast growth and also the failure to obtain transductants of higher resistance by crossing one-step intermediate resistant mutants of different groups (Watanabe \& Watanabe, 1959) seem to support this assumption.

The transduction studies reported in the present series clearly demonstrate that streptomycin resistance is controlled by multiple loci which are not linked to the locus of streptomycin indifference. The transduction of first step into other one-step resistant bacteria does not succeed as mentioned above and it is not known at the present time whether or not this failure is due to some technical reason. If it is not transduced even after technical improvements, it may mean that the first-step mutations are different in action from the second steps and there may be many second steps, third steps and so on. In fact, as discussed above, there is some indication that the second steps may be different from the first steps.

Streptomycin resistance has been most extensively studied among various kinds of bacterial drug resistances and streptomycin-resistant mutants have been used in various experiments. For example, streptomycin-resistant mutants were used to study the mode of action of streptomycin (Umbreit, Smith \& Oginsky, 1951) and streptomycin resistance has been a favourite marker in studying the kinetics of transformation. Although most of the streptomycin resistant mutants used in these studies may be assumed to be streptomycin indifferent from the way they were described to behave, some of them may have been intermediate ones, some of which are one-step and others multiple step. It is evident from the present studies that streptomycin indifference behaves in a different way from intermediate resistance and intermediate resistance can be grouped genetically into multiple classes. It 
would not be surprising, therefore, if they would behave in different ways from each other and if their biochemical mechanisms were different. Accordingly, studies which employ different mutants may produce different results.

Newcombe \& Nyholm (1950) and Demerec (1950) reported that streptomycin dependence is alleleic to complete resistance. In the present studies the isolation of dependent mutants was attempted in order to study their alleleic relation to indifference by transduction but the mutation rates of strains LT-2 and LT-7 to streptomycin dependence seem to be extremely low. From more than 10 cultures and from more than 200 colonies which were completely resistant to streptomycin, no dependent colonies were recovered. Hashimoto (personal communication) found that the infection of dependent mutants of Escherichia coli strain B with $\mathbf{P} 1$ phage from indifferent mutants gave nondependent transductants on agar without streptomycin, and most of these transductants were found to be completely resistant (indifferent) to streptomycin. His results seem to confirm the previous conclusions of Newcombe \& Nyholm (1950) and Demerec (1950).

We are very grateful to Dr Francis J. Ryan for generously giving us a chance of working in his laboratory, for valuable suggestions and discussions in conducting this work and also for much help in writing the manuscript. Our thanks are also due to Dr M. Demerec for kindly supplying his strains.

This work was supported in part by research grants from the U.S. Public Health Service, the National Science Foundation and the American Cancer Society.

\section{REFERENCES}

Demerec, M. (1948). Origin of bacterial resistance to antibiotics. J. Bact. 56, 63.

Demerec, M. (1950). Reaction of populations of uninuclear organisms to extreme changes in environment. Amer. Nat. 84, 5.

Newcombe, H. B. \& Nyнolm, M. H. (1950). The inheritance of streptomycin resistance and dependence in crosses of E. coli. Genetics, 35, 603.

SAGER, R. (1954). Mendelian and non-mendelian inheritance of streptomycin resistance in Chlamydomonas reinhardi. Proc. nat. Acad. Sci., Wash. 40, 356.

Umbreit, W. W., Smith, P. H. \& OGInsky, E. L. (1951). The action of streptomycin. V. The formation of citrate. J. Bact. 61, 595.

Watanabe, T. (1954). Genetic studies on the mechanism of acquired streptomycinresistance in microorganisms. Keio J. Med. 3, 193.

Watanabe, T. \& Watanabe, M. (1959). Transduction of streptomycin resistance in Salmonella typhimurium. J. gen. Microbiol. 21, 16.

(Received 18 July 1958) 